\title{
DISTANÁSIA: ENTRE O PROLONGAMENTO DA VIDA E O DIREITO DE MORRER DIGNAMENTE
}

\section{DYSTHANASIA: BETWEEN THE LIFE EXTENSION AND THE RIGHT TO DIE WITH DIGNITY}

\author{
Alice Pompeu Viana ${ }^{1}$ \\ Julianna Moreira Reis ${ }^{2}$
}

\section{RESUMO}

Durante o século XX, surgem novas técnicas e medicamentos capazes de prolongar a vida. Contudo, um prolongamento irracional do processo vital de um ser humano que não possui mais condições dignas de viver poderá acarretar uma morte lenta e dolorosa. A distanásia, em outros termos, se caracteriza como tratamento médico cujos potenciais benéficos para o paciente em fase terminal são nulos ou improváveis, incapazes de superar os seus potenciais maléficos. No contexto, o presente trabalho pretende demonstrar que negar o direito de morrer a tal paciente é atentar contra o direito à vida, assim como contra a dignidade humana.

Palavras-chave: Morte; Distanásia; Direito à Vida; Direito de Morrer; Dignidade da Pessoa Humana.

\begin{abstract}
During the XX century, arise new techniques and drugs that can prolong life. However, an unreasonable extension of the vital process of human being that does not have dignified conditions of living it could result in a slow and painful death. Dysthanasia is characterized as medical treatment whose beneficial potentials for the terminal patient are non-existent or unlikely, they are not able to overcome their maleficent potentials. In the context, the present study aims to demonstrate that to deny the right to die to such patient is violate the right to life, as well as to harm the human dignity.
\end{abstract}

Keywords: Death; Dysthanasia; Right to Life; Right to Die; Human Dignity.

\footnotetext{
${ }^{1}$ Mestre em Direito Público pela Universidade do Vale do Rio dos Sinos - UNISINOS, Rio Grande do Sul, (Brasil). Advogada. Professora. Especialista em Direito Processual Civil pela Universidade do Sul - UNISUL. E-mail: alice@ cesvale.com.br

${ }^{2}$ Mestre em Direito Público pela Universidade do Vale do Rio dos Sinos - UNISINOS, Rio Grande do Sul, (Brasil). Servidora Pública. Especialista em Direito Eleitoral pela Universidade Federal do Piauí UFPI. E-mail: juliannamoreirareis@ hotmail.com
} 


\section{INTRODUÇÃO}

Não se pode dizer exatamente em que momento a humanidade percebeu que a vida é finita e nem de que modo passou a ritualizar a morte. O que a História demonstra é que as concepções e a ritualística sobre a morte foram se modificando ao longo do tempo e de acordo com cada cultura.

Algumas sociedades conceberam-na apenas como uma passagem, acreditando que aqueles que realizaram tal passagem ainda continuariam "deste lado", sob uma invisibilidade. Já na idade média, a morte era anunciada por uma cerimônia, sendo encarada como um processo em que tanto o morto, quanto os familiares e amigos, se despediam e declaravam os seus últimos desejos e frustrações.

No romantismo, na primeira metade do século XIX, a atitude das pessoas perante a morte se apresenta mais natural, como consequência mesmo da vida. Assim, o diagnóstico médico de morte era aceito de forma simples e clara, sem necessidade de maiores questionamentos ou informações. Essa postura correspondia ao modelo moral, social e estético do romantismo. Numa fase seguinte, demonstra-se maior interesse pela doença, inserindo-se o médico no seio da família, de modo que a única preocupação deste é o diagnóstico. Aqui, o paciente não é informado de seu estado real de saúde, estando à mercê das decisões daquele profissional.

Em uma terceira fase, caracterizada a partir do século $\mathrm{XX}$, diante das novas pesquisas e descoberta de técnicas e medicamentos, cresceu o sentimento de repugnância pela morte, buscando-se sua postergação. É nesse contexto que, em se tratando especialmente de pacientes em fase terminal, surge a necessidade de o paciente conquistar o poder de tomar decisões sobre sua saúde e sobre sua vida.

Nesse sentido, o presente trabalho, após realizar uma análise da morte, a partir de uma perspectiva histórico-cultural, explanará os institutos da eutanásia, do suicídio assistido, da ortotanásia e da distanásia. Embora todos eles mereçam, haja vista a temática envolvida na pesquisa, é em torno desse último fenômeno que se constrói a problemática desse artigo: uma vez que se caracteriza como tratamento médico cujos potenciais benéficos para o paciente em fase terminal são nulos ou improváveis, incapazes de superar os seus potenciais maléficos, a distanásia não geraria uma aparente colisão entre o direito à vida e o princípio da dignidade da pessoa humana? 
Tal questionamento será, na medida em que a extensão desse trabalho permite, desenvolvido no último tópico.

\section{A MORTE - UMA PERSPECTIVA HISTÓRICO-CULTURAL}

Não se sabe ao certo em que momento o homem apercebeu-se da finitude da vida e nem de que modo as sociedades passaram a ritualizar a morte. Conforme relata Dastur (2002), dentre os escritos sobre a morte, o mais antigo que se tem notícia relata a epopeia mesopotâmica de Gilgamesh, que data do segundo milênio antes da era atual. Tal documento relata perigosa viagem empreendida por Gilgamesh, quando da descoberta da doença de seu amigo Enkidu, em busca de remédio que servisse para evitar a morte deste último e

É assim que Gilgamesh, após a morte de Enkidu, ficou obcecado com o que aconteceu a seu amigo e, temendo sofrer o mesmo fim, se revolta contra este prazo inevitável que parece, contudo, inscrever-se na própria natureza das coisas e se impõe inutilmente à procura do que lhe permitisse escapar da lei universal da morte [...] (DASTUR, 2002, p. 14).

A partir de então, pode-se dizer que as concepções e a ritualística sobre a morte foram se modificando ao longo do tempo e de acordo com cada cultura. Algumas culturas conceberam-na apenas como uma passagem, acreditando que esta era caracterizada apenas como uma "vida invisível", mas aqueles que realizaram tal passagem ainda continuariam “deste lado", senão vejamos:

\footnotetext{
Uma antropologia histórica da morte mostra, com efeito, que os homens das sociedades arcaicas repugnavam a ideia de uma destruição definitiva e total e acreditavam que os mortos continuavam a levar ao nosso lado uma vida invisível e não cessavam de intervir no curso da existência daqueles que chamam a si mesmos de vivos. Aqui a ruptura entre mortos e vivos não é definida e a morte se vê mais que integrada ao ciclo da vida [...] (MORIN apud DASTUR, 2002, 17/18).
}

A ritualística que envolve a fase terminal da vida também se modifica durante o tempo e nas diferentes culturas. Na idade média, a morte era anunciada por uma cerimônia, pois para se acostumar com ela era necessário certo período de tempo. Assim, a morte era encarada como um processo em que tanto o morto, quanto os familiares e amigos, se despediam e declaravam os seus últimos desejos e frustrações. A morte repentina era caracterizada como castigo, sendo considerada infamante e imoral. Segundo Philippe Ariès (1977, p. 12): 
Furtar-se ao aviso da morte era expor-se ao ridículo. A crença de que a morte mandava aviso atravessou séculos e podemos encontrá-la nos dias de hoje no imaginário popular, em histórias, contos e causos. Esta morte que se anuncia não deveria ser, portanto, repentina e inesperada, se o fosse poderia ser interpretada como cólera divina; assim, a morte repentina era considerada infamante e vergonhosa.

Nesse cenário, na idade média, os rituais católicos encerravam-se com o enterro do corpo morto. Este, em um primeiro momento, era realizado nas igrejas e basílicas, pois se acreditava que o corpo morto deveria ser protegido pelos santos cujas imagens encontravamse nos altares. Após o crescimento populacional e migração para as cidades passou a ser impossível o enterro dentro das igrejas, de modo que estes locais passaram a ser reservados aos eclesiásticos e àqueles que por nobreza e mérito se distinguiram nos serviços a Deus e nas causas públicas. Nessa época se criaram os cemitérios, localizados próximos às igrejas onde os indivíduos deveriam ser enterrados, excluídos destes os indignos como, por exemplo, os suicidas.

A evolução da atitude humana perante a morte é descrita por Philiphe Ariès em seu livro "A história da morte no Ocidente desde a Idade Média”. Em artigo intitulado "O doente, a família e o médico", o autor relata as atitudes humanas perante a morte no decorrer dos séculos, fazendo compilações de textos desenvolvidos pela população da época e seus anseios, medos e atitudes perante a morte. Esclarece Ariès (1977, p. 170): "Neste artigo, proponho-me a mostrar como a nossa civilização ocidental passou a exaltação da morte na época romântica (princípio do século XIX) para a recusa da morte em nossos dias".

Neste artigo, Ariès (1977, p. 170) inicia as observações pela descrição da atitude perante a morte da Família La Ferronay, no ano de 1834 (fase da complacência para com a morte). A família, composta pelos pais e por dez filhos, viu-se dizimada pela tuberculose, doença do século, de modo que todas as mortes foram relatadas por uma das irmãs. Um documento fundamental, que descreve, com auxílio de documentos irrefutáveis, as atitudes perante a morte e a maneira de morrer das pessoas muito jovens.

Nesta época, a atitude das pessoas perante a morte era mais natural, aceitando-a como um desaguar obrigatório da vida. A máxima da época parece ser aquela de que tudo que está vivo um dia morrerá. Assim, "não havia obsessão do diagnóstico, não por medo do resultado, mas por indiferença à peculiaridade da doença, ao seu caráter cientifico" (ARIÈS, 1977, p. 171). O diagnóstico médico de morte era aceito de forma simples e clara, sem necessidade de maiores questionamentos ou informações. Observe-se que o doente era tratado 
pelo médico, mas o diagnóstico já era certo, qual seja, a "evolução do mal" e, por fim, a morte. Nesta fase da descrição vê-se que a morte é encarada, sentida, observada e, porque não dizer, "aproveitada".

Como expõe Ariès (1977, p. 173/174):

\begin{abstract}
A morte é encarada aqui como um acidente previsto, que não faz parar a vida das famílias. Esta observação, um pouco amarga permite-nos compreender que a imagem não era muito antiga. Correspondia ao modelo moral, social e estético do romantismo. Este compreendia bem o ritual tradicional da morte: adeus aos sobreviventes, confissão religiosa, caráter público da agonia do luto, tal como se conservava nas classes populares. Mas o romantismo acrescentava a tudo isso uma dramatização e uma sentimentalidade nova [...] (ARIÈS, 1977, p. 173/174)
\end{abstract}

A fase intermediária acerca da atitude sobre a morte é descrita por Ariès (1977, p. 175) com base em uma obra de Tolstói, em novela intitulada Três Mortos, de 1859. Nesta fase, demonstra-se maior interesse pela doença, inserindo-se o médico no seio da família, de modo que a única preocupação deste é o diagnóstico. Neste momento, a morte não é mais vista de forma romantizada como dantes. Assim, "Algumas dezenas de anos após a morte dos La Ferronay, os odores da morte e o bacio do doente grave tornaram-se inconveniências".

Ainda nesta fase, o ministrar de remédios como o ópio e a morfina tentam dar cabo à dor e aliviar a vida do paciente, sem que lhe seja dada a completa informação sobre seu estado de saúde. Aqui, o paciente não é informado de seu estado real de saúde, estando à mercê das decisões do médico.

Para caracterizar essa falta de informação e a necessidade crescente de "dar voz" ao paciente terminal, Ariès (1977, p. 176) finda a análise da novela de Tolstói:

\begin{abstract}
Um dia, enfim, I.I (Ivan Ilitch) revolta-se. Volta-se para a parede, atitude denunciada por sociólogos americanos (B.G Glaser e A.L Strauss) como a do moribundo pouco cooperante, que recusa comunicar com o pessoal médico. Manda passear a mulher que lhe fala de remédios: "Deixe-me morrer em paz". Já não se dá ao trabalho de ocultar as suas queixas. Venceu as mentiras, esqueceu as conveniências. Receio bem que se trate da embarrassilingly graceless dying, que Glaser e Strauss nos dizem ser temida pelas equipas técnicas clínicas dos hospitais.
\end{abstract}

Em uma terceira fase, caracterizada a partir do século XX, diante das novas pesquisas e da descoberta de novas técnicas e medicamentos, cresceu o sentimento de repugnância pela morte, buscando-se que a vida finde o mais tarde possível.

Nessa linha de pensamento, Ariès (1977, p. 178/179) relata a história do Padre Dainville que, diagnosticado com leucemia, "se vê em um leito de hospital com dois tubos 
inalatórios nas narinas e um tubo expiratório que lhe fechava a boca, não sei que aparelho para lhe aguentar o coração, um braço sob perfusão e outro sob transfusão e na perna a tomada do rim artificial". Por fim, o Padre arranca a máscara da boca e diz: "Estão a privarme da minha morte".

Verifica-se que, àquela época, as palavras do padre já demonstravam a necessidade de abandono do paternalismo e substituição deste pelo consentimento livre e esclarecido do enfermo. Assim, desenvolveu-se o princípio da autonomia do paciente, sendo que hoje fala-se em "empowerment health, apoderamento sobre a saúde, ou seja, o paciente conquistou o poder de tomar decisões sobre sua saúde e sua vida" (RIBEIRO, 2014), de modo que a autonomia lhe confere tanto o direito de viver, quanto o direito de morrer. Nesse sentido, assim se pronuncia Claus Roxin (2005, p. 23):

\begin{abstract}
se o paciente recusa a operação que salvaria sua vida, ou a necessária internação numa unidade de tratamento intensivo, deve o médico abster-se de tais medidas e, se for o caso, deixá-lo morrer. Esta solução é deduzida, corretamente, da autonomia da personalidade do paciente, que pode decidir a respeito do alcance e da duração de seu tratamento.
\end{abstract}

Veja-se que a noção sobre a morte e a atitude perante a mesma de todos os entes envolvidos - paciente, família e médico - evoluiu de forma sequenciada: desde a sua aceitação como uma simples notícia à necessidade de maior informação do paciente e da família pelo médico (busca pelo diagnóstico), vindo, a seguir, a fase de "medicalização do sentimento da morte", em que se observa o difícil enfrentamento do momento final. Essa evolução culmina/explica/justifica hoje com/a dificuldade das legislações em aceitar práticas de abreviação da vida como a eutanásia e o suicídio assistido.

Assim, a morte é na verdade um processo $^{3}$ e que deve ser encarado como tal, especialmente no que se refere às informações que o médico fornece ao paciente doente e aos seus familiares para que estes possam decidir qual caminho percorrer até o final dele. Nesse ponto, diante de um paciente em fase terminal, não deixam de ser invocados institutos como a eutanásia, o suicídio assistido, a ortotanásia e a distanásia. Embora todos eles mereçam, haja vista a temática envolvida na pesquisa, ao menos um breve apontamento, é esse último fenômeno que constitui o objeto da pesquisa, merecendo melhor digressão. É o que se propõe a seguir.

\footnotetext{
${ }^{3}$ Registre-se que a legislação brasileira reconhece a morte a partir da detecção da morte cerebral (morte do córtex cerebral), conforme exposto no artigo $3^{\circ}$ da Lei 9.434/1997, que dispõe acerca da doação de órgãos.
} 


\section{BREVES DISTINÇÕES ENTRE EUTANÁSIA, SUICÍDIO ASSISTIDO, DISTANÁSIA E ORTOTANÁSIA}

A eutanásia e o suicídio assistido são procedimentos médicos que visam abreviar a vida do paciente incuravelmente doente que sofre com dores insuportáveis e que, por isso, não deseja mais viver. Eutanásia, vocábulo grego, pode ser pode ser traduzida como "boa morte" ou "morte sem sofrimento". Trata-se de método de antecipação da morte utilizada quando o paciente é diagnosticado com doença incurável e que lhe causa diversas dores, fazendo com que este prefira a morte ao sofrimento.

Em conceito explicativo acerca do modo de agir durante a prática da eutanásia discorre Andrew C. Varga (2001, p. 234):

\footnotetext{
Eutanásia significa, em geral, proporcionar uma morte fácil e indolor a um paciente que está morrendo, em virtude de uma enfermidade fatal. A morte pode ser induzida pelo próprio paciente, sem conhecimento ou cooperação de outras pessoas. Ou pode ser efetuada por outros, a pedido do paciente ou com seu consentimento. Em todos esses casos teremos a eutanásia voluntária. Se a morte for induzida contra a sua vontade ou sem o consentimento do paciente, falamos em eutanásia involuntária.
}

Sobre a eutanásia, o ordenamento jurídico brasileiro, até o presente momento, não aceita tal prática e nem há decisões de Tribunais Superiores que permitam abreviar a vida, considerando o ato homicídio.

Importante ainda conceituar o conceito de suicídio assistido. Conhecido também como suicídio eutanásico (CANO, 1999, p. 45), o suicídio assistido configura-se como conduta própria do sujeito que deseja retirar sua vida sem a intervenção de terceiro. Assim, não se pode confundir o suicídio eutanásico com o suicídio genérico, pois as causas fundamentadoras de um e outro são diversas, como esclarece Carlos Maria Romeo Casabona (1994, p. 427):

La eutanasia realizada por el proprio interessado conceptualmente no coincide con el
suicidio: la primera seria la aceleración del momento de la muerte que se presenta
mas o menos cercana como único medio de se abreviar el sufrimento físico y moral
derivado de una enfermidad terminal o de uma minusvalía irreversible (causa, p. ej.
un acidente), mientras que el segundo consiste en quistarse uno mismo violenta y
voluntariamente de la vida que ya non queres ser vivida por cualquier outro motivo
y en circunstacias diferentes. Sin embargo, desde la perspectiva de su tratamento
penal hay que assimilarla com aquél: en ambos os casos existe la vontade directa de
murir e el acto de privarse de la vida; el suicidio seria el género, la eutanasia la
espécie. Esta valoración juridica es importante, quando en la eutanasia é involucrado
un terceiro, porque frequentemente los tipo penales cuyas aplicacións estará em 
juego serán las figuras de participación punible en el suicidio (art. 409, CP), por que aquéllan debe ser tenida em cuenta para las reflexiones que siguén más adelante.

Nessa esteira, as condutas desenvolvidas na prática do suicídio assistido e da eutanásia, embora obtenham o mesmo resultado morte, são realizadas por agentes diferentes. No primeiro caso, postos os meios, o próprio doente retira sua vida, por exemplo, ministrando-se substancia letal. No segundo caso, um médico ou um terceiro intervém no processo de abreviação da vida, empreendendo, por si, por suas próprias mãos, meios para retirar a vida do doente.

Como se verifica, os institutos eutanásia e suicídio assistido são técnicas de antecipação da morte. Já a ortotanásia e a distanásia, objeto do estudo, têm o objetivo de amenizar as dores do paciente e conferir ajuda psicológica aos seus familiares ante o momento da perda do ente querido, sendo procedimentos que visam preservar a vida. Estas últimas serão explanadas a seguir.

O conceito de distanásia possui uma origem epistemológica grega e resulta do prefixo dis, que significa afastamento, mal feito, e do vocábulo thanatos, que, por sua vez, significa morte. Assim, define-se a distanásia como sendo o afastamento da morte, ou seja, é o prolongamento da vida do ser humano que não possui mais condições dignas de viver, o que resultará em uma morte lenta e dolorosa.

Nas palavras de Renato Lima Charnaux (2005, p. 01), distanásia "é morte lenta e com excessivo sofrimento". Caracteriza-se, a distanásia, nas palavras do autor, como "tratamento médico fútil, quando ministrado em pacientes portadores de graves moléstias, para as quais não há solução facilmente identificável pela ciência médica". No mesmo sentido, também discorrendo sobre a distanásia, Joaquim Antônio César Mota (2014) aponta que a distanásia é "ação médica cujos potenciais benéficos para paciente são nulos ou tão pequenos ou improváveis que não superam os seus potenciais maléficos”.

O Código de Deontologia Médica de 1931 dispunha em seu artigo 16 que "um dos propósitos mais sublimes da medicina é sempre conservar e prolongar a vida", sendo que a interpretação dada a esse artigo pela comunidade médica era de que deveria ser perseguida a vida a qualquer custo, mesmo que essa obstinação terapêutica causasse dor e sofrimento ao paciente terminal.

Contudo, houve a substituição do referido Código pelo Código de Ética Médica de 1988, o qual, suprimindo a redação do artigo 16, estabeleceu, em seu Capítulo I, incisos, II, V, VI, XVI e XXIII, que o alvo da atenção do médico é a saúde da pessoa, devendo ele sempre 
agir em benefício do paciente, entendimento este mantido no atual Código que entrou em vigor em 13 de abril de 2010.

Nesse sentido, na prática da medicina, o médico deve zelar pela aplicação dos princípios da bioética, especialmente pelos princípios da autonomia do paciente, sendo respeitoso ao desejo deste de se submeter ou não a determinado tratamento e da não maleficência, buscando não causar qualquer dano ao paciente quando do tratamento. Sobre o princípio da não maleficência, dispõe Luciano de Freitas Santoro (2012, p. 131) que

Há necessidade de observância pelo médico, ainda do principio da não maleficência devendo se abster de proceder com condutas que causem dano intencional no seu paciente. Mais ainda, somente deve exercer o seu mister para o bem daquele sob seus cuidados. [...]

Por outro lado, a distanásia é resultado de um "problema humano profundo, a relutância em aceitar a morte como fim de nossa existência" (VARGA, 2002, P. 230), tal qual explicitado no tópico anterior. Leo Pessini assevera que a maioria dos profissionais da medicina ainda hoje não está preparada para lidar com a morte, já que eles foram educados para salvar vidas e, em regra, o médico associa a morte do paciente ao fracasso na prestação de seus serviços.

Já a ortotanásia advém dos vocábulos gregos orthós, que significa normal, correto e thánatos, que, conforme esclarecido anteriormente, significa morte. O termo foi cunhado por Jacques Roskam, no Primeiro Congresso Internacional de Gerontologia, em Liège, Bélgica, significando que "entre encurtar a vida humana através da eutanásia e a sua prolongação pela obstinação terapêutica existiria uma morte correta, justa, isto é, aquela ocorrida no seu tempo oportuno" (1950, p. 709/713). Assim, este termo designa a morte natural, sem interferência da ciência e contrapondo-se aos conceitos anteriormente citados.

Nessa linha de entendimento, Eduardo Luiz Santos Cabette (2013, p. 25) aponta que

\begin{abstract}
A ortotanásia consiste na "morte a seu tempo", sem abreviações do período vital (eutanásia), nem prolongamentos irracionais do processo de morrer (distanásia). É a morte correta mediante a abstenção, supressão ou limitação de todo tratamento fútil, extraordinário ou desproporcional, ante a iminência da morte do paciente, morte esta a que não se busca (pois o que se pretende aqui é humanizar o processo de morrer, sem prolongá-lo abusivamente), nem se provoca (já que resultará da própria enfermidade que o sujeito padece).
\end{abstract}

Assim, "enquanto na eutanásia a morte decorre de um ato praticado voluntariamente pelo médico, na ortotanásia o seguimento natural da doença e seu agravamento são 
independentes das ações ou omissões do facultativo", de modo que "o fundamento principal da ortotanásia é a absoluta ineficácia de uma intervenção médica extremada para evitar a morte do paciente" (ALVES, 2001, P. 32).

Nesse sentido, observa-se que a ortonásia se apresenta como o meio termo entre a eutanásia e a distanásia. No entanto, esta pode ser admitida num sentido extremamente restrito. O Código de Ética Médica, em seu artigo 14 determina que o médico, quando observar a existência de doença incurável e terminal, não abreviando a vida, deve se limitar a “oferecer todos os cuidados paliativos disponíveis, sem empreender ações diagnósticas inúteis ou obstinadas, levando sempre em consideração a vontade expressa do paciente ou, na sua impossibilidade, de seu representante legal".

A partir de uma análise trans e multidisciplinar, pode-se verificar que a Igreja Católica já se pronunciou acerca da ortotanásia, autorizando a supressão de cuidados de reanimação em pacientes que estejam em morte iminente e inevitável. O Papa Pio XII manifestou-se no sentido de que o homem não é obrigado a se submeter a uma carga extraordinária para conservar a própria vida ${ }^{4}$.

Após a exposição dos termos em epígrafe, nesse momento do presente trabalho, cumpre questionar se, diante da morte iminente, o médico realmente deveria agir. Considerando-se que é em torno dela que se constrói a problemática desse artigo, a distanásia não geraria uma aparente colisão entre o direito à vida e o princípio da dignidade da pessoa humana?

\section{O DIREITO DE MORRER DIGNAMENTE}

Embora seja complexa a tarefa de definir o que vem a ser o vocábulo vida, neste trabalho será abordada uma acepção jurídica da palavra, como um valor supremo na ordem constitucional, que orienta, informa e dá sentido último a todos os demais direitos fundamentais, segundo Paulo Gustavo Gonet Branco (2009, p. 34).

Em verdade, o direito fundamental à vida é mero reconhecimento jurídico de situação de fato, vez que o homem não existe sem a vida. Assim, consistindo pressuposto inerente ao ser humano não seria necessário que qualquer das legislações viesse a garantir tal

\footnotetext{
4 Declaração do Papa Pio XII. $\quad$ Disponível em: http://www.vatican.va/holy_father/pius_xii/encyclicals/documents/hf_p-xii_enc_21041957_fidei-donum_it.html. Acessado em: 28 de julho de 2014.
} 
direito, pois sem ele nenhum outro se concretiza. Neste passo, "a vida humana não é ficção jurídica, é realidade pura, independente de qualquer norma ou lei, expressão de certo poder estatal." (SILVA, 2006, p. 37).

Além disso, adota-se também a concepção de vida exposta por José Afonso da Silva (2001, p. 200/201):

\begin{abstract}
Vida, no texto constitucional (art. $5^{\circ}$, caput), não será considerada apenas no seu sentido biológico de incessante auto-atividade funcional, peculiar à matéria orgânica, mas na sua acepção biográfica mais compreensiva. Sua riqueza significativa é de difícil apreensão porque é algo dinâmico, que se transforma incessantemente sem perder sua própria identidade. É mais um processo (processo vital) que se instaura com a concepção (ou germinação vegetal), transforma-se, progride, mantendo sua identidade, até que muda de qualidade, deixando então de ser vida para ser morte. Tudo que interfere em prejuízo deste fluir espontâneo e incessante contraria a vida.
\end{abstract}

Nesse sentido, pode-se afirmar que a Constituição Federal Brasileira de 1988 elenca, como direito fundamental inviolável, o direito à vida. A proteção constitucional refere-se não somente ao direito de estar vivo, de não morrer, de manter-se vivo. A Constituição Brasileira pretende uma proteção mais global e complexa no sentido que os indivíduos têm o direito de gozar a vida de forma digna. A vida digna abrange também o direito de viver dignamente, possibilitando ao ser humano a liberdade, o emprego, a família, seus bens e o completo aproveitamento destes durante o processo vital.

Diante do exposto, uma vez que o processo vital termina com a morte, a morte também deveria ser efetivada de forma digna? Percebe-se que o tema deste está intrinsecamente ligado ao conceito de dignidade humana, sendo indispensável estabelecer o que venha a sê-lo, bem como a quais limites deve, o médico, ou mesmo o próprio paciente, obedecer, quando do final da vida.

No contexto, o primeiro apontamento sobre a dignidade humana é a dificuldade que se apresenta em defini-la. No quesito, torna-se pertinente a ponderação de Carmém Lúcia Antunes Rocha ao asseverar a "ambiguidade e a porosidade do conceito jurídico da dignidade da pessoa humana", bem como seu papel "diversificado e impreciso" nos ordenamentos jurídicos, "sendo elemento em construção permanente mesmo em seu conteúdo".

Já Antônio Junqueira de Azevedo (2002) aponta que a dignidade humana seria "um conceito jurídico indeterminado; utilizada em norma, especialmente constitucional, é um princípio jurídico", tal qual foi acolhida na Constituição da República Federativa, eis que aparece entre os princípios fundamentais. 
Ainda sobre a dificuldade de se estabelecer o conteúdo do termo dignidade humana Ingo Wolfgang Sarlet (2008, p. 16/17) expõe:

\begin{abstract}
[...] não há como negar [...] que uma conceituação clara do que é efetivamente a dignidade da pessoa humana, inclusive para efeitos de definição de seu âmbito de proteção como norma jurídica fundamental, se revela no mínimo difícil de ser obtida. Tal dificuldade, consoante exaustiva e corretamente destacada na doutrina, decorre, certamente (ao menos também) da circunstância de que se cuida de um conceito de contornos vagos e imprecisos, caracterizado por sua "ambiguidade e porosidade", por sua natureza necessariamente polissêmica, bem como por um forte apelo emotivo, muito embora tais atributos não possam ser exclusivamente atribuídos à noção de dignidade da pessoa humana.
\end{abstract}

Contudo, em busca de estabelecer um conceito satisfatório de dignidade da pessoa humana, Ingo Wolfgang Sarlet apontou a existência de dimensões da dignidade, com vistas a compreender o real sentido da expressão, em especial no campo jurídico: a dimensão ontológica, a intersubjetiva, a histórico-cultural e a dimensão dupla, analisadas a seguir.

A dimensão ontológica "vincula a concepção da dignidade como uma qualidade intrínseca da pessoa humana e, de modo geral, comum às teorias da dignidade como dádiva ou um dom conferido ao ser humano pela divindade ou pela própria natureza" (SARLET, 2008, P. 19). Portanto, a dimensão ontológica da dignidade aponta que esta é inerente ao ser humano, nasce com ele e com ele permanece durante toda a sua existência não dependendo de qualquer ato de reconhecimento ou aceitação.

No mesmo sentido, Nordenfelt (2004, p.78) apresenta essa mesma variação da dignidade com o nome de menschenwürde, a qual pertenceria a todo ser humano na mesma medida e extensão, não podendo ser perdida enquanto o sujeito estiver vivo e justificando a condição dos beneficiários dos direitos humanos.

A dimensão intersubjetiva ou relacional destaca o ser humano como ser social, de modo que o reconhecimento de sua dignidade pessoal deve ir além também para reconhecer a dignidade do outro. O homem é eminentemente um ser social (ARISTÓTELES, 1988) e assim o sendo possui uma dimensão jurídica individual e outra social. A dimensão individual reconhece, conforme relatado anteriormente, a condição de dignidade a cada ser humano em sua individualidade. Já a dimensão relacional aponta essa necessidade do reconhecimento da dignidade em uma dimensão jurídica social.

No que se refere a essa dimensão de dignidade intersubjetiva Jurgen Habermas (2004, p. 62/63) considera que esta, numa acepção moral e jurídica, está intimamente relacionada à simetria das relações humanas, de tal sorte que sua intangibilidade resulta 
justamente das relações interpessoais marcadas pela recíproca consideração e respeito, de tal sorte que apenas no âmbito do espaço público da comunidade da linguagem, o ser natural se encontra indivíduo e pessoa dotada de racionalidade. Perceba-se a presença do elemento respeito, quando da tentativa de definição da dignidade humana. Nesse sentido, Bernard Baertschi (2009, p. 190) assevera que o conceito de dignidade engloba os conceitos de direito e de respeito, pois

Tratar um ser com respeito é aceitar os limites dos nossos próprios interesses em nome dos dele, mesmo se estivermos na posição de impor os nossos, porque reconhecemos que o ser a respeitar tem um valor particular, seja em razão de sua eminência, seja por causa de sua fraqueza.

Francis Fukuyama (2003, p. 33) também sacramenta a ideia da dimensão relacional da dignidade, quando aponta que como seres humanos "partilhamos da humanidade comum que permite a todo ser humano se comunicar potencialmente com todos os demais seres humanos no planeta e entrar numa relação moral com eles".

Já a dimensão histórico-cultural da dignidade aponta que a definição desta é variável conforme o tempo e o espaço em que se analisa. Assim, a definição de dignidade jamais se apresentará como um conceito estanque, de categoria axiológica aberta, vez que se configura como um conceito em permanente estado de desenvolvimento e construção, em virtude do pluralismo e da diversidade de valores observados nas sociedades contemporâneas (SARLET, 2008, p. 27).

Como última das dimensões da dignidade, Sarlet (2008, p. 30) aponta para uma dimensão dupla, ao mesmo tempo negativa e prestacional:

a dignidade possui uma dimensão dúplice, que se manifesta enquanto simultaneamente expressão da autonomia da pessoa (vinculada a ideia de autodeterminação no que diz com as decisões essenciais a respeito da própria existência), bem como a necessidade de sua proteção (assistência) por parte da comunidade e do Estado [...].

Observe-se que, nesta concepção, a dignidade seria um limite para a atuação estatal, pessoal e social de modo a impedir que qualquer indivíduo seja "coisificado", seja por ação própria ou de terceiro (dimensão negativa). Ao mesmo tempo, representa um dever para o Estado, que deve pautar as suas condutas, decisões e objetivos sempre na intenção de preservar a dignidade humana (dimensão prestacional). Veja-se que o Estado possui não só o poder, mas também o dever de promover a dignidade humana, não só evitando atos 
atentatórios à mesma, mas garantido políticas ativas que venha a proteger essa mesma dignidade, garantindo o mínimo existencial para cada um dos indivíduos.

Essa dimensão negativa da dignidade, tal como exposta acima, que se encontra vinculada à ideia de autodeterminação da pessoa humana, quanto às decisões essenciais a respeito da própria existência, assemelha-se ao desdobramento da dignidade proposto por Nordenfelt (2004, p. 71-76) como dignidade de identidade. Segundo esse prisma, a dignidade se apresenta ligada à integridade e à autonomia do corpo e da mente do ser humano e, em muitos casos, à sua própria autoimagem. Segundo a autora, pode-se dizer que a dignidade de uma pessoa em estado vegetativo permanente está mitigada ou, até mesmo, temporariamente perdida, em função das limitações que essa deficiência lhe acarreta na vida em sociedade. Nesse quadro, podem ser vislumbrados então os pacientes em fase terminal.

É nesse ponto que se pretende esclarecer, nos limites em que a extensão do presente estudo permite, os questionamentos formulados alhures. $\mathrm{O}$ ordenamento jurídico brasileiro vem reconhecendo a vida como um direito indisponível, por se entender que o direito de dispor livremente de si, o jus in se ipsum, seria contrário ao direito alheio e ao interesse público (FRANÇA, 1992, P. 377). Perceba-se que essa postura engessa a noção da dignidade em sua perspectiva relacional, assim como em sua dimensão prestacional.

Diante de uma situação em que se apresenta um paciente em fase terminal, faz-se necessária uma ponderação, faz-se inevitável um juízo de proporcionalidade, no sentido de levar em conta a dimensão negativa da dignidade, no sentido de se considerar a autonomia da pessoa, que decidirá sobre sua vida livremente com base em informações prestadas por uma equipe médica. Se a morte se constitui em uma fase última da vida, como exposto, se existe um direito à vida, que vai além do direito de estar vivo, sendo um direito a uma vida digna; pode-se dizer que há, então, um direito de morrer dignamente.

Desse modo, retomando-se que a distanásia se caracteriza como tratamento médico cujos potenciais benéficos para o paciente em fase terminal são nulos ou improváveis, incapazes de superar os seus potenciais maléficos, pode-se afirmar que ela afronta o direito a uma morte digna.

Quando o direito nega o direito de morrer a um paciente em fase terminal, entendendo ser a vida indisponível, está atentando contra o próprio direito à vida, assim como contra a dignidade humana, por impor uma vida conduzida com dor e sofrimento. 


\section{CONCLUSÃO}

Como visto, as concepções e a ritualística acerca do fim da vida foram se modificando ao longo do tempo e de acordo com cada cultura. A atitude perante a morte de todos os entes envolvidos - paciente, família e médico - evoluiu de forma sequenciada: desde a sua aceitação como uma simples notícia à necessidade de maior informação do paciente e da família pelo médico (busca pelo diagnóstico), vindo, a seguir, a fase em que se observa o difícil enfrentamento do momento final.

Essa última fase, caracterizada a partir do século XX, surge num contexto em que novas pesquisas e novas descobertas de técnicas e medicamentos. Observa-se um crescente sentimento de repugnância pela morte, que leva à busca de que a vida finde o mais tarde possível.

É nesse cenário que o Código de Deontologia Médica de 1931 dispunha em seu artigo 16 que "um dos propósitos mais sublimes da medicina é sempre conservar e prolongar a vida", sendo que a interpretação dada a esse artigo pela comunidade médica era de que deveria ser perseguida a vida a qualquer custo, mesmo que essa obstinação terapêutica causasse dor e sofrimento ao paciente terminal.

De qualquer modo, a maioria dos profissionais da medicina ainda hoje não está preparada para lidar com a morte, pois eles foram educados para salvar vidas e, em regra, o médico associa a morte do paciente ao fracasso na prestação de seus serviços.

Nesse cenário, observa-se a distanásia como o prolongamento da vida do ser humano que não possui mais condições dignas de viver, o que resultará em uma morte lenta e dolorosa. Em outros termos, a distanásia se caracteriza como tratamento médico cujos potenciais benéficos para o paciente em fase terminal são nulos ou improváveis, incapazes de superar os seus potenciais maléficos.

Pode-se dizer, numa primeira análise, que a distanásia estaria em concordância com o direito fundamental à vida. Contudo, a Constituição Federal de 1988, em seu art. 5º ao elencá-lo, refere-se não somente ao direito de estar vivo, de não morrer, de manter-se vivo, pois pretende uma proteção mais global e complexa no sentido que os indivíduos têm o direito de viver dignamente.

Além disso, é certo que o processo vital se instaura com a concepção, transforma-se, progride, até que muda de qualidade, finda, e deixa de ser vida para ser morte. Se a morte faz parte desse processo, não deveria também ser efetivada de forma digna? 
É fato que o ordenamento jurídico brasileiro reconhece a vida como um direito indisponível, por se entender que o direito de dispor livremente de si, o jus in se ipsum, seria contrário ao direito alheio e ao interesse público. Contudo, diante de uma situação em que se apresenta um paciente em fase terminal, faz-se necessária uma ponderação, faz-se inevitável um juízo de proporcionalidade, no sentido de levar em conta a dimensão negativa da dignidade, no sentido de se considerar a autodeterminação, autonomia da pessoa, que decidirá sobre sua vida livremente com base em informações prestadas por uma equipe médica.

Se a morte se constitui em uma fase última da vida, como exposto, se existe um direito à vida, que vai além do direito de estar vivo, sendo inclusive um direito a uma vida digna; pode-se dizer que há, então, um direito de morrer dignamente.

Desse modo, pode-se afirmar que a distanásia afronta o direito a uma morte digna. Ainda, quando o direito nega o direito de morrer a um paciente em fase terminal, entendendo ser a vida indisponível, está atentando contra o próprio direito à vida, assim como contra a dignidade humana, por impor uma vida conduzida com dor e sofrimento.

\section{REFERÊNCIAS}

ALVES, Ricardo Barbosa. Eutanásia, Bioética e Vidas Sucessivas. Sorocaba: Brazilian Books, 2001.

ARIÈS, Philippe. História da morte no Ocidente. Rio de Janeiro: Francisco Alves, 1977.

ARISTÓTELES. Política. 2. ed. São Paulo: Martins Fontes, 1998.

AZEVEDO, Antônio Junqueira. Caracterização jurídica da dignidade da pessoa humana. Revista dos Tribunais, v. 797, p. 12, mar. 2002. Disponível em: <http://www.usp.br/revistausp/53/09-junqueira.pdf>. Acesso em: 28 de setembro de 2014.

BAERTSCHI, Bernard. Ensaio filosófico sobre a dignidade. Antropologia e ética das biotecnologias. Tradução Paula Silva Rodrigues Coelho da Silva. São Paulo: Loyola, 2009. 
BRANCO, Paulo Gustavo Gonet. Curso de Direito Constitucional. 4. ed. rev. e atual. São Paulo: Saraiva, 2009.

BRASIL. Código de Deontologia Médica de 1931. Disponível em: http://www.portalmedico.org.br/arquivos/codigo_deontologia medica(1931).pdf. Acesso em: 28 de julho de 2014.

BRASIL. Código de Ética Médica, Publicado no D.O.U. de 24 de setembro de 2009, Seção I, p. 90. Retificação publicada no D.O.U. de 13 de outubro de 2009, Seção I, p.173.

http://www.cremego.cfm.org.br/index.php?option=com_content $\& v i e w=\operatorname{article} \& \mathrm{id}=21000 \& \mathrm{It}$ emid=474. Acesso em: 28 de julho de 2014.

CABETTE, Eduardo Luiz Santos. Eutanásia e ortotanásia: comentários à Resolução 1.805/06 CFM. Aspectos éticos e jurídicos. Curitiba : Juruá, 2013.

CANO, Ana Maria Marco del. La eutanásia: estudo filosófico-jurídico. Madri: Marcial Pons, 1999.

CASABONA, Carlos Maria Romeo. El derecho y la bioética ante los limites de la vida humana. Madrid: Centro de Estudos Ramón Areces, 1994.

CHARnAUX, Renato Lima. A Distanásia e a Dignidade do Paciente. Rio de Janeiro: Renovar, 2005.

Contornos atuais da eutanásia e da ortotanásia: bioética e biodireito. A necessidade de controle social das técnicas médicas. Boletim do Instituto Manoel Pedro Pimentel, n. 11, p. 20-26. São Paulo, mar. 2000.

DASTUR, Françoise. A Morte: ensaio sobre a finitude. Trad. Maria Teresa Pontes. Rio de Janeiro; DIFEL, 2002. 
Declaração do Papa Pio XII. Disponível em: http://www.vatican.va/holy_father/pius_xii/encyclicals/documents/hf_pxii_enc_21041957_fidei-donum_it.html. Acessado em: 28 de julho de 2014.

FRANÇA, Genival Velosa. Direito Médico. 5. ed. São Paulo: Fundo Editorial BYC, 1992.

FUKUYAMA, Francis. Nosso Futuro pós-humano: Consequências da revolução da biotecnologia. Tradução de Maria Luiza X. de A. Borges. Rio de Janeiro: Rocco, 2003.

HABERMAS, Jurgen. O Futuro da Natureza Humana. A caminho da eugenia liberal? Trad. Karina Jannini. São Paulo: Martins Fontes, 2004.

MOTA, Joaquim Antônio César. Quando um Tratamento torna-se fútil? Disponível em: http://revistabioetica.cfm.org.br/index.php/revista_bioetica/article/view/291/430. Acesso em: 5 de março de 2014.

NORDENFELT, Lennart. The Varieties of Dignity. Healthy Care Analysis, n. 2, v. 12, p. 69-81, june 2004.

RIBEIRO, Diaulas Costa. Autonomia: viver a própria vida e morrer a própria morte. Disponível em: http://www.scielo.br/scielo.php?script=sci_arttext\&pid=S0102311X2006000800024\&lng=pt $\& n r m=i s o \&$ tlng=pt. Acessado em: 23 de agosto de 2014.

ROCHA, Carmém Lucia Antunes. O princípio da dignidade da pessoa humana e a exclusão social. Disponível em: <http://egov.ufsc.br/portal/sites/default/files/anexos/3222938415-1-PB.pdf>. Acesso em: 29 de setembro de 2014.

ROSKAM, Jacques. Purely, vegetative survival in cerebrosclerosis: dysthanasia, orthothanasia. Revue Médicale de Liège, outubro de 1950. 
ROXIN, Claus. A tutela penal da vida humana. São Paulo: Editora Damásio de Jesus, 2005.

SANTORO, Luciano de Freitas. Morte Digna: o direito do paciente terminal. Curitiba: Juruá, 2012.

SARLET, Ingo Wolfgang. As dimensões da dignidade da pessoa humana: uma compreensão jurídico-constitucional aberta e compatível com os desafios da biotecnologia. In: SARLET, Ingo Wolfgang; LEITE, George Salomão. Direitos Fundamentais e Biotecnologia. São Paulo: Método, 2008.

SILVA, José Afonso da. Curso de Direito Constitucional Positivo. 19. ed. São Paulo: Malheiros, 2001.

SILVA, José Carlos Sousa. Direito à Vida. Porto Alegre: Sergio Antônio Fabris, 2006.

VARGA, Andrew C. Problema de Bioética. Trad. Guido Edgar Wenzel. São Leopoldo: Unisinos, 2001. 